\title{
Surgeons stitch it together
}

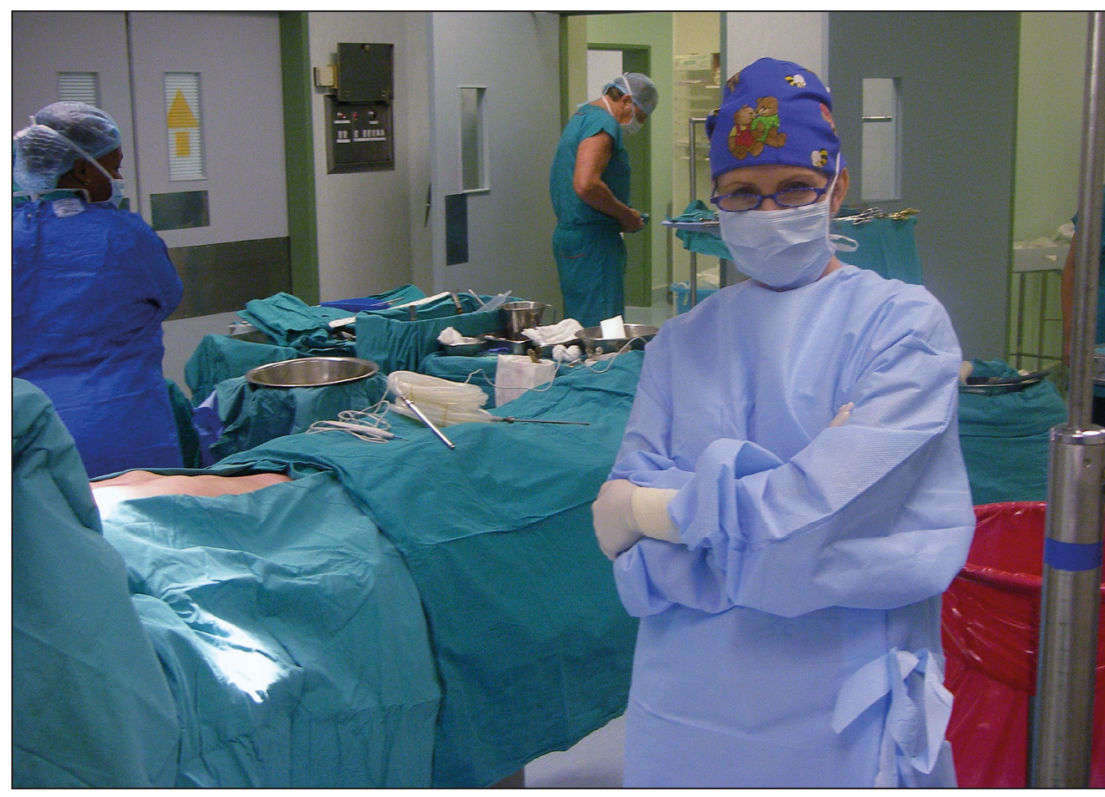

Chairperson of the Federation of South African Surgeons, Dr Elmin Steyn, in theatre.

Nine surgical associations have combined to form a powerful new lobbying and negotiating body which will increase their clout in preparation for, among other things, the National Health Insurance (NHI), new ethical tariffs, procedural fees and in attracting better congress funding.

Nearly 5 years in the making and called the Federation of South African Surgeons (FOSAS), the new body will allow smaller surgical and related bodies to punch well above their weight in national health-related forums. So far the umbrella body consists of the Association of Surgeons of South Africa (ASSA), College of Surgeons of South Africa, South African Association of Paediatric Surgeons (SAAPS), South African Colorectal Society, South African Surgical Research Society (SRS), South African Society of Endoscopic Surgeons (SASES), South African Society of Surgeons in Training (SASSiT), Surgicom, Trauma Society of South Africa (TSSA) and the Vascular Society of South Africa (VASSA). However the Chairperson, Dr Elmin Steyn, invited all other surgical disciplines and societies linked to surgery to join, emphasising that FOSAS was not created in opposition to the South African Medical Association (SAMA) (currently hard at work trying to woo breakaway specialists back into their fold), but as a 'political grouping with clear mandates.

She said the new body was also open for affiliation by multi-disciplinary societies for the co-ordination and support of their surgical interests. 'The aim is to unite groups, not alienate those with a predominantly non-surgical focus', she said.

The concept of FOSAS was first suggested at a May 2007 meeting before being jointly developed by Professors Martin Veller (Secretary General) and Sats Pillay, with a joint administrative office set up in October 2008 and a Constitution and Articles of Association consolidated last year. Member societies are invited to make use of the joint secretariat for management of membership and other admin, for which they will pay on a pro rata basis

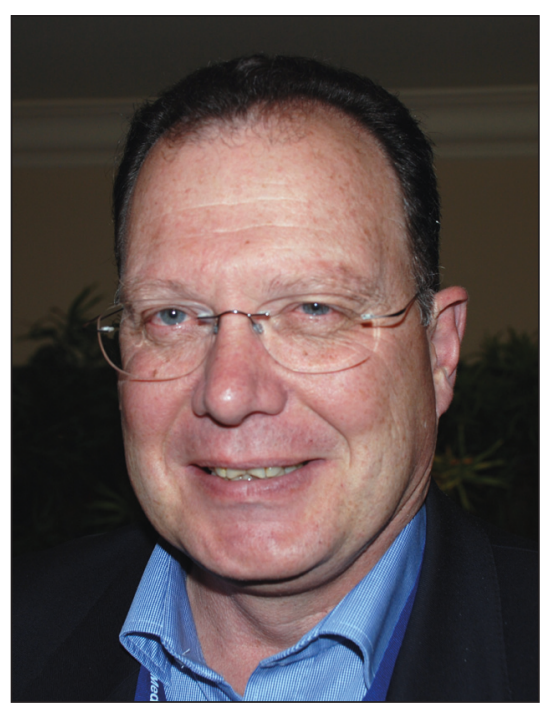

Professor Martin Veller, Secretary General of the new Federation of South African Surgeons. depending on membership numbers and admin requirements.

Each member society remains responsible for their own financial administration and the FOSAS admin costs are kept to a minimum. FOSAS membership will be free, Steyn emphasised.

The editors of the indexed South African Journal of Surgery are also considering incorporating other societies into a sub-title to boost the magazine's circulation.

Asked why it took so long to breathe life into such an obviously needed body, Veller, Head of Surgery at Wits University, said it was about finding the right people (who had to do things part-time) with the right focus, adding, 'there was no politics at all'.

\section{New body shows political savvy}

He confirmed that FOSAS had convened a meeting between SAMA and the breakaway SA Private Practitioners Forum in an attempt to mediate and resolve long-standing differences.

'Basically FOSAS felt uncomfortable being pulled between the two and we wanted to understand what was going on, he explained.

It was agreed at a mid-February meeting this year, facilitated by Professor Alan Rothberg, Acting Head of the School of Clinical Medicine at Wits University, that both sides work towards a memorandum of understanding so that they could begin discussing 'nuts and bolts'.

Rothberg, previously medical advisor to the Medscheme Group and head of Paediatrics at Wits and that university's chief of therapeutic sciences, was considered the ideal mediator because of his background and history. The rift came after private practitioners grew increasingly disgruntled by what they perceived as SAMA not focusing sufficiently on private practice issues. It coincided with heightened anxiety over the first clumsy outlines of the NHI, and was precipitated by some controversial and uncontested remarks about the private sector by then SAMA chairperson, Dr Kgosi Letlape, who later apologised. ${ }^{1}$

Chris Bateman

chrisb@hmpg.co.za

1. Bateman C. 'Loose cannon' Letlape says he was 'misinterpreted'. S Afr Med J 2009;99:132-136. 